\title{
Few Clips in Oral \& Maxillo-Facial Surgery
}

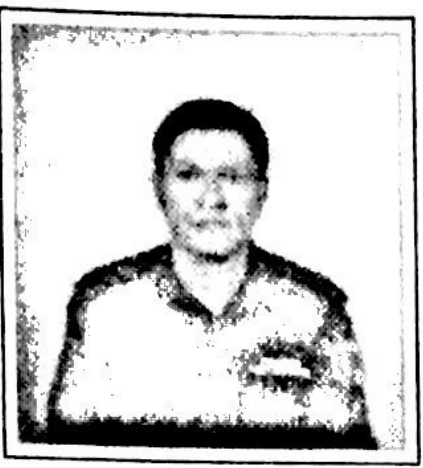

ELt. Col. Dr. Bishnu Bahadur Basto HOD Dental Surge

Oral \& Maxillo-Facial Surgery is the specialty of Dentistry includes the diagnosis, surgical and adjunctive treatment of disea injuries and defects including both the functional and aesth aspects of the hard and soft tissues of the oral \& maxillofa regions. Few Clips of our operated cases(Pre-Op. \& Post Op. Vie are given below to make concerned people familiar with the typ cases performed in Oral \& Maxillo-Facial Surgery so that refe, will be easy.
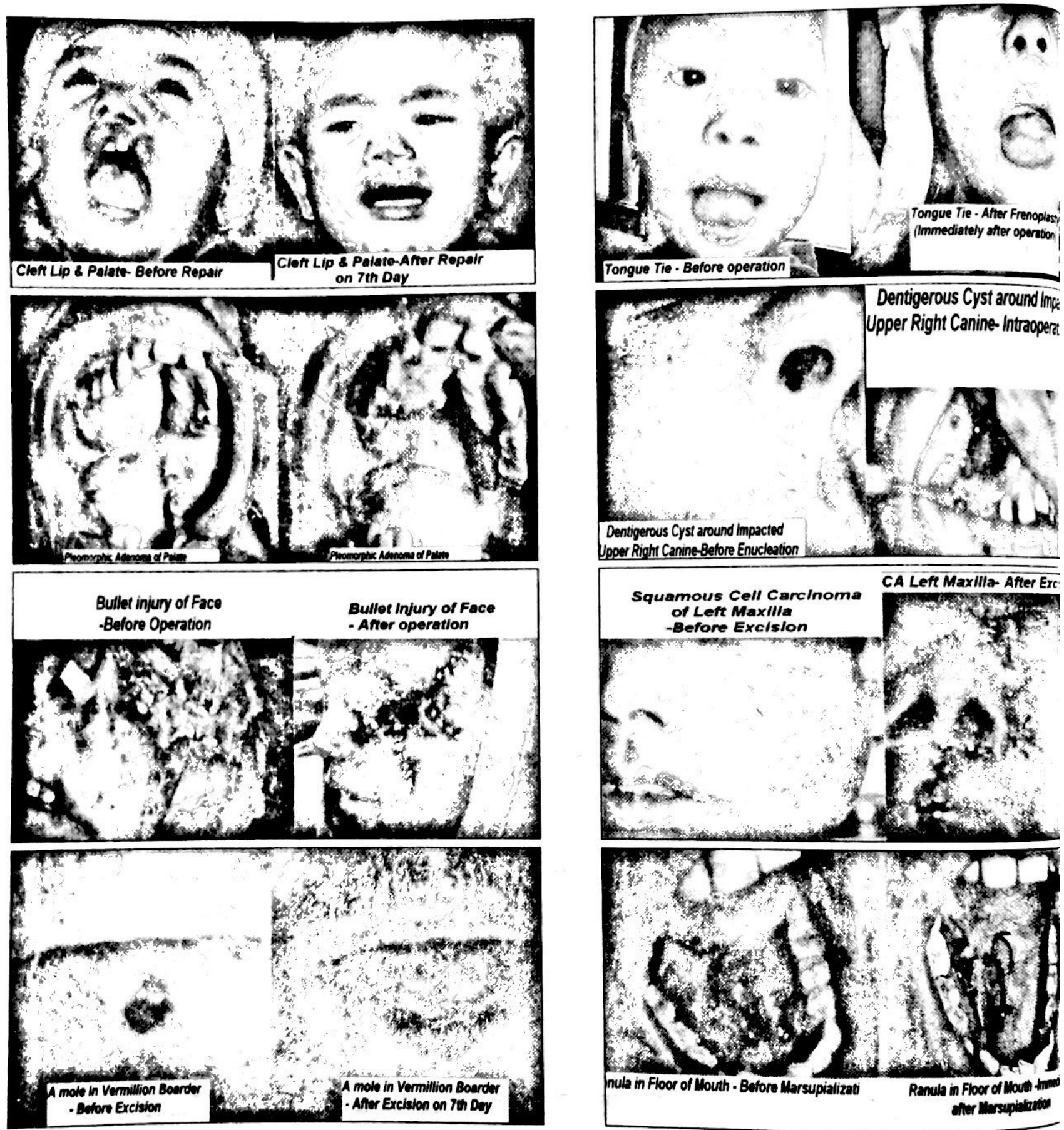